\title{
Couple relationships in families with dependent children after a diagnosis of maternal breast cancer in the United Kingdom: Perspectives from mothers and fathers
}

\author{
Roslyn Corney, $\mathrm{PhD}^{\mathrm{a}}$, Shuby Puthussery, $\mathrm{DrPH}^{\mathrm{b}}$, and Jane Swinglehurst, $\mathrm{MSc}^{\mathrm{a}}$ \\ aDepartment of Psychology, Faculty of Education and Health, University of Greenwich, London, UK;

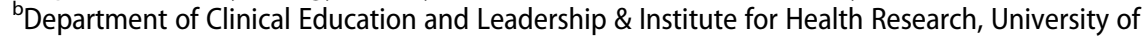 \\ Bedfordshire, Luton, Bedfordshire, UK
}

\begin{abstract}
This article examines the facilitators and the barriers to couple relationships in families in the UK with dependent children after a diagnosis of maternal breast cancer. Qualitative data were collected through in-depth semi-structured interviews with 23 participants, including 10 couples and three women whose partners did not take part. Recorded interviews were analyzed using a thematic approach identifying themes and patterns in the interview transcripts and categorizing them using a framework. Key individual and contextual factors perceived as barriers or facilitators to couple relationships included: being a "young" family with young children, frustration and resentment from male partners, women's reactions to the illness, individual communication styles, differing needs for "personal space," body image concerns, and social support. Findings indicated the need for strengthening "family focus" in services with adequate support for male partners. Health and family services should consider variability in the experiences of couples with dependent children and be sensitive to the needs of partners alongside the women.
\end{abstract}

\section{KEYWORDS}

breast cancer; young families; partners; couple relationships; mothers

\section{Introduction}

Breast cancer diagnosis and treatment comes with an array of personal and psychosocial consequences not only for patients but also for their partners and families. Breast cancer is the most common cancer in the UK and the most common cancer among females (Cancer Research UK, 2013). The impact of a life-threatening disease, its treatment and side effects, coupled with concerns regarding recurrence and an uncertain future can all potentially cause considerable distress for those affected by cancer, their partners, and families. On the other hand, family context, particularly as

CONTACT Shuby Puthussery, DrPH shuby.puthussery@beds.ac.uk Department of Clinical Education and Leadership \& Institute for Health Research, University of Bedfordshire, Putteridge Bury - Rm32, Hitchin Road, Luton, Bedfordshire LU2 8LE, UK. 
experienced through close interpersonal relationships, is shown to be one of the most important factors in adjustment to cancer. Relationship between partners is particularly important as it has been consistently shown that good partner support is significantly associated with better adaptation to breast cancer, improved quality of life, and lower levels of negative psychological reactions (Coyne \& Anderson, 1999; Rodin et al., 2007; Skerrett, 1998). Partners acknowledging cancer; sharing feelings, needs, moods, and emotions; and being sensitive and empathetic help women to cope better with the illness (Holmberg, Scott, Alexy, \& Fife, 2001; Manne et al., 2004; Manne \& Badr, 2008; Pistrang \& Barker, 1995; Skerrett, 1998). It has been indicated that inadequate support received from partner cannot be fully compensated by support from friends and family (Coyne \& De Longis, 1986; Pistrang \& Barker, 1995). One family member's illness is postulated to affect the entire family, and both partners in an intimate relationship are likely to experience distress when one of them has a serious illness (Minuchin, 1974; Northouse, Templin, Mood, \& Oberst, 1998). Studies have indicated higher levels of distress and psychological morbidity among partners of women affected by breast cancer compared with the general population (Ben-Zur, Gilbar, \& Lev, 2001; Lindholm, Rehnsfeldt, Arman, \& Hamrin, 2002; Nakaya et al., 2010; Omne-Ponten, Holmberg, Bergstrom, Sjoden, \& Burns, 1993).

\section{Couple relationships after a diagnosis of breast cancer}

Studies that have explored couple relationships after breast cancer diagnosis have reported varied findings. While some studies report increased strain and conflict within the relationship during the diagnosis and treatment phase leading to marital discord (Carter, Carter, \& Siliunas, 1993, Northouse et al., 1998, Wai Ming, 2002), others have found that marital satisfaction or relationship breakdown after diagnosis is not significantly different from the general population (Dorval, Maunsell, Taylor-Brown, \& Kilpatrick, 1999; Ganz, Rowland, Desmond, Meyerowitz, \& Wyatt, 1998). Overall, it would appear that about one-third of couples do not adequately manage to cope with the illness (Manne, 1998).

Different factors have been posited by researchers and practitioners regarding what might contribute to increased relationship difficulties after breast cancer diagnosis. The most commonly cited risk factor is the presence of existing relationship difficulties prior to diagnosis. Couples already experiencing difficulties tend to find the illness as a major additional source of strain on the relationship (Carter, Carter, \& Siliunas, 1993; Northouse, 1989). Prolonged emotional distress in either the woman or the partner following diagnosis also contributes to relationship difficulties (Naaman, Radwan, \& Johnson, 2009; Omne-Ponten et al., 1993). Sexual difficulties tend to be another risk factor for diminishing quality of couple relationships (Ghizzani, Pirtoli, Bellezza, \& Velicogna, 1995). Approximately onethird of women and their partners experience sexual difficulties after the woman is diagnosed with breast cancer (Bloom, Stewart, Chang, \& Banks, 2004; Northouse, 1994; Walsh, Manuel, \& Avis, 2005). 
Communication styles between couples have been variably linked to adjustment, coping, cohesiveness, and conflict. Studies of couple interaction, in early breast cancer, have indicated that couples tend to use three main styles of communication: open engagement, mutual avoidance (also known as protective buffering), and demand-withdraw (Manne, Dougherty, Veach, \& Kless, 1999; Zunkel, 2002). Couples adopting open engagement are able to express their emotions and talk about their feelings (Stanton et al., 2000; Weihs, Enright, \& Simmens, 2002). Those who use mutual avoidance tend not to talk about their emotions, feelings, or worries. Demand-withdraw style suggests a cycle of demand (sometimes termed "pursue") and withdrawal. In most cases, the woman is the pursuer as she wishes to talk. However, these demands result in further withdrawal by her partner (Manne et al., 2006). Among various communication patterns, open engagement has been linked to positive adjustment and coping, greater couple cohesiveness, and reduced conflict, whereas the other two are indicated to be less adaptive especially if there is a discrepancy between partners on the degree of its use (Manne, Dougherty, Veach, \& Kless, 1999; Stanton et al., 2000; Traa, De Vries, Bodenmann, Den Oudsten, 2015; Weihs et al., 2002). Interactions between partners can also be explained in light of family system theorists' argument that family systems maintain patterns of behavior determined by a "feedback loop" consisting of positive and negative feedback (Whitchurch \& Constantine, 1993). Engaging in adequate dyadic coping styles, with couples reacting as a unit rather than as individuals, has been linked to higher relationship quality after breast cancer diagnosis (Rottmann et al., 2015; Traa et al., 2015).

More than half of female breast cancer cases diagnosed in the UK each year are women aged less than 65 years (Cancer Research UK, 2013). Earlier studies have reported that more than a quarter of women diagnosed with breast cancer have children living at home (Bloom \& Kessler, 1994) and these mothers tend to experience difficulties in meeting the needs of their children in addition to their own needs (Dunn \& Steginga, 2000). In families with children living at home, the partner may have to take responsibility for organizing the day-to-day lives of their children, meeting their emotional as well as physical needs (Forrest, Plumb, Ziebland, \& Stein, 2009). While most mothers and fathers want to keep life "normal" for their children (Forrest et al., 2009; Stiffler, Haase, Hosei, \& Barada, 2008), this may not be possible during treatment and couples could get totally overwhelmed, feeling isolated and helpless, with increased parental responsibilities on top of everything else (Rayson, 2001). Reviews of studies on parents' experience following a diagnosis of cancer have revealed themes that are important to parents, such as being a good parent, telling the children, and maintaining routine at home, highlighting their support needs (Semple \& McCance, 2010).

It has been indicated that young mothers with children are a particularly vulnerable group and need support to manage their fears of having a recurrence and to cope with problems in intimacy (Ares, Lebel, \& Bileajew, 2014). Couple relationships are most vulnerable in the first 10 years of marriage, often after the transition 
to parenthood (Baucom, Porter, Kirby, Gremore, \& Keefe, 2005; Twenge, Campbell, \& Foster, 2003). It would appear that the illness can have a greater impact on couple relationships in families with dependent children, but very little is known about couple relationships in these families following a diagnosis of maternal breast cancer. Studies exploring both maternal and paternal perspectives on the impact of maternal breast cancer on couple relationships are also relatively few (Forrest et al., 2009; Hilton, Crawford, \& Tarko, 2000).

This article explores the facilitators and the barriers to couple relationships in families with dependent children (under the age of 18 years) based on maternal and paternal perspectives.

\section{Methods}

The data presented in this article are derived from in-depth, semi-structured interviews conducted in the UK with 23 participants including 10 couples and three women whose partners did not want to take part. The inclusion criteria for participation were that the woman had a first episode of breast cancer 9 or more months ago and was living with a partner and dependent children aged below 18 years at home. The original plan was to include only women who were diagnosed at least 18 or more months prior to contact in order to reduce chances of potential distress arising from talking about their experiences that were very recent. However, this was shortened to 9 months (after further ethics committee agreement) due to difficulties in recruitment. Discussions with convenors of breast cancer support groups indicated that younger women might wish to move on after treatment and do not always want to revisit the past or talk about the experience. During these discussions, it was also suggested that recruitment might be easier if the time lapse between diagnosis and interview was reduced from 18 to 9 months. Women who were undergoing active treatment or those who had recurrent or metastatic cancer were excluded. Following ethics approval from the National Health Service (NHS) ethics committee, participants were recruited from NHS trusts, charities, support groups, and internet forums such as Macmillan. In accordance with ethics approval requirements, recruitment was done through posters displayed in hospitals and leaflets and talks in support groups in England and Wales without the researchers directly approaching potential participants. Details of the study were also added to a Facebook support group for breast cancer and on the Macmillan website. Women, who were interested, could either discuss the study with their breast cancer nurse or with the researchers directly using given contact details. Those who were interested to take part after the initial discussion were given detailed information about the study, about the length of the interview, and the scope of questions. They were also sent an information leaflet, and an appointment was made to interview at a time and venue convenient to the participant.

As Table 1 shows, the women's ages at diagnosis ranged from 31 to 48 years. They were all married and in a heterosexual relationship. The ages of the youngest 
Table 1. Characteristics of participants and their families.

\begin{tabular}{|c|c|c|c|c|}
\hline $\begin{array}{l}\text { First name } \\
\text { (pseudonym) }\end{array}$ & $\begin{array}{l}\text { Recruitment } \\
\text { source* }\end{array}$ & $\begin{array}{l}\text { Women's age } \\
\text { at diagnosis }\end{array}$ & $\begin{array}{l}\text { Children's names } \\
\text { and ages at diagnosis (years) }\end{array}$ & $\begin{array}{c}\text { Time since } \\
\text { diagnosis (months) }\end{array}$ \\
\hline Diana/Mark & SG & 31 & Chloe (8 months) & 41 \\
\hline Barbara/David & SG & 44 & $\begin{array}{l}\text { Catherine (20), Emily (17), Susie } \\
\text { (13) }\end{array}$ & 21 \\
\hline Chrissy/Peter & $\mathrm{BCN}$ & 31 (8 months pregnant) & Beth (5), Matthew (unborn) & 12 \\
\hline Rebecca/John & SG & 40 & Jenny (8), Alex (4) & 26 \\
\hline Elaine /Stephen & SG & 39 & Sophie (12), Tom (8) & 33 \\
\hline Susan/Tony & SG & 46 & Amy (19), Daniel (16), Dylan (9) & 42 \\
\hline Fiona/Michael & SG & 44 & $\begin{array}{l}\text { Josh (23), James (20), Alastair } \\
\text { (12), Alice (8) }\end{array}$ & 60 \\
\hline Claire/Oliver & SG & 33 & Sarah (6), Ethan (2) & 10 \\
\hline Fran/Rob & 1 & 44 & Anna (16), William (14), Lisa (10) & 9 \\
\hline Emma/Ben 2 & SG & 44 & Richard (11), Rachel (8) & 14 \\
\hline Elizabeth & SG & 48 & $\begin{array}{l}\text { Megan (22), Grace (17), Scott } \\
\text { (11) }\end{array}$ & 29 \\
\hline Fay & I & 41 & Jessica (14), Darren (11) & 44 \\
\hline Cheryl & SG & 38 & $\begin{array}{l}\text { Annette (12), Hannah (10), Dan } \\
\text { (6) }\end{array}$ & 48 \\
\hline
\end{tabular}

${ }^{*} \mathrm{BCN}$, breast care nurse; I, Internet support group; SG, support group.

children at diagnosis differed markedly from an unborn baby to the age of 13 years. Most couples had two or three children. The woman with only one child was given the diagnosis when this child was 8 months old. The time since diagnosis varied considerably, with three women having had their diagnosis between 9 and 12 months ago. The longest reported time span since diagnosis was 5 years. The treatment regimens varied considerably, including surgery, chemotherapy, and radiotherapy. All the women had undergone surgery, and all but one had chemotherapy and eight had radiotherapy.

All the interviews were conducted by the principal investigator (RC) who has a background in health psychology. Informed consent was taken before the start of the interview. Women and partners were interviewed separately using a flexible topic guide covering aspects such as the participant's story from the time of diagnosis to the date of the interview and the impact on the participant; the views about how the illness/treatments affected the partner and the relationship with the partner; what they told the children about the illness and their views on the impact of the illness on the children and family relationships; what help (if any) had been sought or received for own or partner's emotional well-being and with family relationships; and what alternative/additional information or support might have been helpful either to them or to families in general. Majority of the interviews were conducted face to face in the participants' homes, usually one after the other. Three interviews with partners were conducted over the telephone because of the partner's limited availability. For the majority of couples (8), both partners agreed to take part from the beginning. For the remaining two, the women were interviewed first and their partner agreed to take part later. Three additional women were interviewed without their partner. Two of these women preferred not to ask their partner about their interest to take part in the study. One partner had a number of 
mental health problems of his own, including recovery from long-term alcohol addiction, and the woman felt that the interview might be too distressing for him.

The interviews were conducted in a supportive manner to reduce the possibility of distress. Participants were given the opportunity to take a break and were informed that they did not have to answer any specific questions they did not feel comfortable with and could terminate the interview early if they chose to do so. The average duration of the interview was $90 \mathrm{~min}$. Interviews with partners tended to be slightly shorter. Some partners found it difficult to talk about the experience, and a few were visibly distressed at some point during the interview. Although they were given the opportunity to discontinue the interview at any point, all of them wanted to carry on indicating that they felt better by the end.

All the interviews were audio-recorded with permission from the participants and were transcribed using pseudonyms. The analysis was based on a thematic approach developed by Braun and Clarke (2006). Two researchers conducted the analysis, with one using the software NVivo for qualitative analysis. The analysis was exploratory but not purely inductive in theme generation-a simple framework for categorization of within-case themes was developed based on the topics covered in the interview guide. Each interview was coded with a set of within-case themes based on a meaningful segment of text in the transcript. The themes were subsequently categorized using the originally developed framework. Discussions between the researchers took place at regular intervals, usually after coding every two-three interviews. The researchers undertook a cross-case analysis, based on comparing, collating, and contrasting the transcripts for 23 participants.

\section{Findings}

\section{Facilitators and barriers to couple relationships}

\section{Being a "young" family with young children}

In our study, couples with young children faced unique challenges that were viewed as having a significant impact on their relationship. Six couples in our study had young children (10 years or below) at the time of the interview with three couples reporting associated relationship difficulties. The accounts from couples with young children clearly indicated the stress associated with looking after children in the face of the illness. Two couples with very young children (one couple had a 8 month-old girl, the other had a 2-year-old and a 6-year-old at diagnosis) had gone through major relationship difficulties:

It was just so much of a stress and strain.... They say a baby makes you or breaks you; with that [breast cancer] on top I think it almost did. (Diana, with a baby aged 8 months at diagnosis)

These couples struggled in the face of the disease adjusting to their dual role as a parent and partner, often struggling to keep their relationship intact by attending to each other's needs: 
It has been very bad, our relationship for various reasons, mostly I think Claire feels let down by me emotionally.... I feel that I've had to focus practically on just keeping our four lives ticking over, that I haven't been there for her as well as I could have been emotionally to help her deal with it. (Oliver)

Couples with young children quite often attempted to reduce the impact of the illness on the children and to protect them from the anxieties and difficulties involved in the treatment by trying to keep things as normal as possible, and this sometimes caused considerable additional stress:

I think after my first chemo, it was sports day, and I was determined to go to my daughter's sports day, and it was Alex's first preschool trip on a coach, and I was there like being really brave and thinking I feel like hell, and I'm there. (Rebecca)

Having young children also meant that couples would have much more limited time to spend together as a couple or to attend to each other's needs:

And then you could say about us having time together, but we've had Sarah having tantrums that last for 2 hours and she's telling her teacher mummy's taking too long to get better, how am I supposed to go out with Oliver for an afternoon and leave her when I know full well she's feeling the way she's feeling? (Claire)

The participants indicated that some of the older children and teenagers reacted negatively to their mother's illness by becoming difficult, angry, or resentful, but this tended to present less of a strain on the couple's relationship and cause less division between couples. However, having very young children was not necessarily a negative factor always, as was the case for another couple with young children (a 5-year-old and a new-born baby) whose relationship remained strong throughout. Notably this couple had much more support from relatives and the woman had managed to cope well physically for the majority of the treatment period.

\section{Frustration and resentment in partners}

All the men in our study coped reasonably well with the illness initially, but many partners became stressed, exhausted, frustrated, and resentful eventually. As for them, the illness and treatment meant that the ill partners' needs had to come first and their own needs were secondary, which apparently gave way to frustration and resentment at times, slowly eroding the quality of the couple's relationship. These frustrations were likely to have had built up over time and couples might not have even been aware of it until they became more apparent through particular incidents at later stages of treatment or when the main treatment sessions were finished:

We go all the way up there in the car, and then he had a massive tantrum about pushing me in it [the wheel chair], because I could walk; I wasn't incapable of walking; it was just that I couldn't walk very far and I got very tired and sick. And it was almost like that was his protest about everything, and he's expected to cope with it all and not fuss, and there I am... he didn't ever articulate that, but I think that's what it was. (Elizabeth) 
Although partners quite often recognized that their wives' and children's needs had to come first, they were tired and exhausted both emotionally and physically. Supporting their partner and taking over family duties along with carrying on with their work proved to be exhausting and emotionally draining for partners. As their lives revolved around cancer and surviving the treatment period, the lack of space or time for partners to pursue other interests or activities also added to the stress and frustration:

I suppose the hardest thing to cope with is... our life is still centred around cancer, because like every day Barbara will say this hurts, that hurts... and sometimes you think oh God! tired yes, a bit drained.... But I've never really been depressed over it, or emotional I suppose. (David)

There was recognition among both male and female respondents that such frustration and resentment could have taken its toll on the relationship if circumstances were different:

No matter how strong we were, if I wasn't dealing with it particularly well, I could have been taking it out on him, or pushing him away.... So you could have the strongest marriage in the world but you can see that it could go the other way because it does put a huge, huge strain. (Fay)

However, some men indicated that some of their frustrations and worries could have been reduced if they had had an emotional outlet:

They always talked about Diana, which is obviously the way it should be.... But just once or twice it would be nice if somebody went "Oh how are you doing Mark, do you need anything...?" "Let's go out for a drink or whatever." (Mark)

Emotional support for partners may be particularly important when the woman refuses to talk about the illness to either him or anyone else, thus making it difficult for the partner to confide in friends:

Because you're not allowed to talk about it and you have to pretend it's not happening. No, so yeah, our social life is crap because they know, but they can't say it and the longer it goes, the harder it is, so it's like we've hidden a secret from them [friends]. (Rob)

In general, participants recognized that there was very little emotional support offered to partners. Few people asked how partners were and many partners indicated that there was no one they could easily talk to. Partners did not always want to talk to family and friends as they were fearful of becoming a burden. While all the participants readily recognized that partners need to be supported in order for them to carry on coping and supporting their ill spouse, many accounts from both women and the partners indicated the absence of a "family focus" by health professionals. It was also felt that providing more formal emotional support through breast care nurses, counsellors, or support groups may be difficult for partners to accept. Retrospectively, two of the partners felt that emotional support from outside the family might have been helpful but were unsure whether they would have 
taken it up had it been offered. It was also indicated that if counselling were to be offered to men, it needed to be carefully marketed as a routine service in a way that made it more acceptable, perhaps together with statistics to show how it could help.

\section{Impact of women's reactions to illness}

The women interviewed varied according to their experiences of the illness, treatment regimes, and range of physical reactions and coping mechanisms. Some felt very ill for long periods while others found that the treatments had a much less severe effect. In terms of coping, some tried to make light of the illness, while others were devastated and became anxious and depressed. The women's reactions, both physical and mental, plus their coping mechanisms, were perceived to have an impact on their partner and the relationship. It was harder for the partner when the woman had a tough time, both physically and mentally:

She just sort of got on with it. There was no feeling sorry for herself or anything like that.... You've got to get through this and that's what she did, bless her. (Tony)

For some women, the treatment phase proved to be a particularly stressful period when they had been angry, anxious, and depressed along with perceptions of being "robbed of" special things, and this was felt to affect the relationship as well.

The physical impact of the treatments was another factor; while some women reacted reasonably well, others had had considerable complications that seemed to take a toll on couple and family relationship. The length of treatment was also found to be an important factor that was perceived to have potentially affected the relationship. Three women who had chemotherapy had been feeling ill or incapacitated for some time, and, although their partners found the reserves to cope initially with the family, these gradually wore thin over time:

He was brilliant at the beginning, but I suppose he could only take so much.... I just think it was a build-up of things. I mean somebody can only be so strong for so long on their own. (Claire)

So I was taking a lot on the chin and eventually you just become a little bit deflated don't you? (Mark)

A substantial number of participants mentioned other stresses and life events as well, such as sick children, chronic illness in relatives, or bereavement, which made life more difficult for the partner, their relationship, and the family.

\section{Differences in communication styles}

Staying connected through intimate communication plays a pivotal role in maintaining couple relationships. Some couples undergoing breast cancer treatment in our study faced difficulties in communicating with each other and, thus, giving emotional support to the partner. This came up as a predominant issue for couples 
who reported relationship issues, as all of them experienced problems in talking to each other about the illness after diagnosis:

Obviously we both felt a bit angry about the whole thing as well, so probably maybe we weren't communicating as much as we should have, and talking about how we're feeling. (Diana)

Couples varied according to how much they wanted to talk about the illness; for instance, some female participants indicated that partners often found it easier to cope by not talking about it and they understood and accepted this way of coping:

I'd say he didn't talk about it much. He did, if I wanted to, but yeah, he was just there and we didn't really sort of like be too different. (Fay)

There was some consensus with respect to this among male partners as many mentioned that they were able to cope by being able to switch off from the illness sometimes:

I probably found it easier in some ways not thinking about it too much, but I tried to go to all the appointments and be supportive and everything. (Ben)

There were also instances where the partners felt that the women wanted to keep it to themselves:

Most of our friends would say they didn't know she had been ill... she even carried on working.... She says, "I don't want to be seen to be like this, I don't want the children to see me being sick, I want to just sort of carry on as if I'm normal," which isn't healthy... but for me I'm the opposite, so I didn't have anybody to bellow at or at cry at or talk to about it. (Rob)

Such differences were not always perceived as a problem if both partners preferred not to talk about it too much or they had learnt to accept the difference or when the woman understood that not talking about it was not a signal that their partner did not care:

I don't have the urge to sit around and cry over my disease or... and luckily we're both like that. (Chrissy)

I think we've always been quite close. He doesn't express his feelings very well, but he never has. I think that's the way he is. (Fay)

However, it was a problem, if one of the partners found it difficult or upsetting:

Yeah, you don't know where that's heading. I mean if you're not communicating, I mean to my eyes, I would have thought well that's not good. (Claire)

Such marked differences in illness communication acted as a potential source of tension in the relationship:

There's a tension of wanting to be the provider and the carer, but not being able to be, and having to respect that... it's not sympathy you want, but to get support from others 
because you're not allowed to talk about it and you have to pretend it's not happening. (Rob)

It was also perceived that having other sources of emotional support to relieve some of these stresses might have reduced such interpersonal difficulties:

Or maybe if he had someone to talk to, but it must be quite difficult when nobody wants to talk to you about it... it would have been better if we had looked into having someone to talk to more about it (the cancer). (Diana)

\section{Need for "personal space"}

Couples varied in terms of their need to have time together or to do things on their own. As with communication, this caused little difficulty in the relationship if both partners were similar in this respect. For example, one partner had taken 8 months off work so that he could be with his ill spouse during the whole period of treatment. This "time together" was felt to have strengthened the relationship:

The 8 months... it sounds a bit bizarre, but it was in some ways the worst and in some ways a very fulfilling 8 months in that we did shut out the world, and we did just concentrate on that solidly for 8 months and she was actually incredibly amazing. (Michael)

There were others who liked to have some time apart as they felt that if they are able to rejuvenate individually, they will be better equipped to be their own self:

But my husband works a lot and I actually like that, and he knows that. I don't mind him going off on business trips... I don't know how you say it, but I like to be alone, I like to be by myself. (Chrissy)

However, when couples differed in their needs for "personal space," it appeared to cause difficulties. For example, one of the female participants preferred to go to her hospital appointments alone while her partner wanted to accompany her:

He works hard and he works long hours and he would have come with me, and in some ways I was unkind to him not letting him... so most of the other appointments I've had, I've never had him with me, but I would keep him fully informed. (Fran)

\section{Body image and physical intimacy}

As there is substantial evidence about changes in body image and physical intimacy in women affected with breast cancer, these issues were not explored in detail in our study. However, spontaneous recurrent comments indicated that there had been changes in physical intimacy for some couples with many male partners perceiving body image concerns felt by the women:

I look at Barbara, she looks down at her body, and there's a different perception there because she sees a big gap, you know, whereas you don't actually see it as that, you know. But when you've been married 27 years, the loss of a breast isn't a major issue at all. It's the preservation of her and I. (David) 
Body image concerns appeared to have affected physical relationships in the case of almost half of the couples with some participants explicitly indicating how these changes have "got in the way" of the relationship:

I think it has really got in the way because when you're having your chemo you feel washed out, so you don't want to be intimate, you just... and because it's your breast that they've operated on, it's in the way, so I think that side of things have suffered.... Intimacy - that has gone out the window really. (Rebecca)

However, some of these couples felt to have managed to regain physical intimacy over the years after diagnosis and treatment:

And I think obviously the only other thing that probably takes a big learning curve again is your relationships on the physical side, is again something that has to be relearnt because obviously with the medications, the sex drive isn't as strong on the woman's side, and even if it is, they've got to get mentally in touch with accepting their bodies again... but the physical side has got back to, you know, with a bit of learning again over the years. (Michael)

\section{Buffering social support}

Participants' accounts indicated how important it was to receive support-both practical and emotional from outside the immediate family-for their relationship:

How we'd have got through it, we had fantastic help from family and friends and people who'd turn up with meals and that was the thing that was most useful... I mean I virtually stopped cooking, I just couldn't do anything really. (Elizabeth)

There were instances when participants perceived the nature of the illness and the associated awkwardness acting as barriers for support from friends and other members of the social network:

And it's surprising, when Susan was ill, how many of our friends didn't come round, and I think it was just probably out of awkwardness more than anything, you know. (Tony)

Those without much support were more likely to suggest that the illness and treatments had put so much more pressure on the relationship and the family as a whole. This was particularly the case for the three couples who faced relationship difficulties:

Yeah, it would have made a world of difference if Claire had a decent relative that could take some pressure off of her and me. (Oliver)

Couples with external sources of help tended to feel under less pressure and less stressed. This in turn helped them to cope better with their ill spouse's reactions, whether there were feelings of anger, anxiety, or depression, thus equipping them to invest their time and energy for each other and their children:

Yeah, because if someone said that they would come round and clean the house, I mean that would have helped us no end and if we could maybe have had a babysitter for a few 
hours and there again, that would have helped a lot. And someone to come in and maybe sit with Claire if I went out or something. (Oliver)

\section{Discussion and implications for policy and practice}

This study builds on previous work on the impact of breast cancer on couple relationships by exploring the experiences of married couples in families with dependent children after a first episode of maternal breast cancer. As this was a qualitative study based on a sample of 23 participants mostly recruited through support groups, our findings are not necessarily representative of the experiences of all couples in similar situations. However, our methods created a suitable "space" for respondents to freely express their lived experiences and in-depth perspectives. The study also offered us the opportunity to explore both partners' perspectives separately, as we interviewed women and partners individually. Studies focusing on couple relationships based on both maternal and paternal perspectives in families with dependent children are relatively sparse, and our findings provide some valuable insights for policy and practice in this regard.

As indicated by the participants in general, and the couples who had gone through relationship difficulties in particular, breast cancer could undoubtedly put huge stress on couple relationships and take a toll if couples are not adequately resourced physically, socially, and psychologically to meet the associated challenges. There seemed to be a variation and range among our participants according to how well couples were resourced to face these challenges and how well they managed to cope. Our findings suggest that couple relationships in families with young children are particularly vulnerable, especially when the level of practical and emotional support from extended family or friends is low. In general, couple relationships tend to be most vulnerable during first-time parenthood with increased chances of relationship breakdown or deterioration in relationship quality (Cowan \& Cowan, 2000; Twenge, Campbell, \& Foster, 2003). Adjustments in the relationship at this time are usually necessary to cope with having a young child, placing the couple's own needs on the "back burner" (Cowan \& Cowan, 2000). Coping with breast cancer can prove to be particularly difficult at this time if couples are unable to acquire appropriate support to manage the competing demands placed on them. We found that keeping things as normal as possible for the children is a goal for most parents in this situation and this can cause considerable additional stress to them (Dunn \& Steginga, 2000). As recognized by some participants in our study, there could be a relationship between their child's difficult behaviors and their own personal reactions and emotions. As argued by family systems theorists (Whitchurch \& Constantine, 1993), family processes are of paramount importance to both short- and long-term adjustment and behavioral outcomes for children. For example, Watson et al. (2006) found that maternal depression after breast cancer had an adverse effect on children. Such evidence further points to the importance of supporting both parents and their relationship to enhance outcomes for children. 
The extent of the impact of the illness on the partner is another key potential influence on couple relationships that came up in our study. Some partners in our study felt heavily pressured and became frustrated and resentful. While most partners accrued great importance to being seen strong and keeping family life "as normal," this often meant that they had to keep their fears, worries, and emotions to themselves, causing additional strain on them (Badr, 2004; Fergus \& Gray, 2009; Forrest et al., 2009; Hilton, Crawford, \& Tarko, 2000). As found by Northouse (1988) more than two decades ago, partners continue to voice the need for someone they could easily talk to when it is difficult for them to confide in their partner, extended family, or friends. Part of this may be due to their need to be seen as positive and strong (Fergus \& Gray, 2009; Hilton et al., 2000). Although detailed indications of what can be of help to partners were limited in our study, it was quite clear that a general recognition of the difficulty of their position by health professionals could be of help. Emotional support may not always need to be delivered through formal sophisticated support systems, but partners may benefit from being given time to talk through their feelings and worries to an empathetic listener. Practical and emotional support, given together, may work best.

We found the woman's physical and emotional reactions to the illness and treatments as key influences on the couple's relationship. When the woman reacted and coped well, it was far less stressful for the partner (Naaman et al., 2009; Omne-Ponten et al., 1993) and when partners were less stressed, they were more supportive and caring. Among the couples in our study, in situations where the woman had a number of physical complications, was laid low by the chemotherapy, or was chronically angry, anxious, or depressed, it appeared to get increasingly difficult for partners to cope with the negative reactions over time, although coping with these reactions may be possible in the beginning (Moyer \& Salovey, 1999; Naaman et al., 2009). In such situations, partners are very likely to need greater support to cope with the relationship and in caring for the ill partner. This would imply that clinicians should not necessarily assume that partners will always be able to offer immediate and reliable emotional support to women diagnosed with breast cancer.

There were differences between partners in our study according to how much they wanted to talk about the illness. We found that many couples avoided talking to each other about their fears for the future as this was usually seen as a way of protecting their partner, reducing any unnecessary pain both for themselves and the partner (Foy \& Rose, 2001). As suggested by Badr (2004), this may not pose problems in the relationship if couples had some shared understanding in this respect or had learnt to accept the difference. Emotional support from others may be particularly important when there is a discrepancy between partners about how much they wanted to talk about the illness, how they coped with the illness, and the need for time to be on their own. Sources of external support, including support groups, may be helpful in enabling a discussion of these fears (Gray, Fitch, Davis, \& Phillips, 1997). Couples in our study differed in their need for "personal 
space," and consistent with previous study findings, this can cause difficulties if there are substantial differences between the couple in this respect (Lichtman, Taylor, \& Wood, 1987)

About one-third of couples experience deterioration in physical intimacy with difficulties reported more commonly among younger women (Bloom, Stewart, Chang, \& Banks, 2004; Northouse, 1994; Walsh, Manuel, \& Avis, 2005). All the female participants in our study were under the age of 50 years and were likely to have received toxic treatments over long treatment periods. The physical effects of hormonal cancer treatment are likely to be greater for younger women. They are also likely to be more vulnerable to be distressed by changes in body image, feelings of potential loss of womanhood and fertility, and changes in sexual functioning (Baucom et al., 2005; Ganz, Greendale, Petersen, Kahn, \& Bower, 2003). Majority of the couples in our study experienced deterioration in physical intimacy with associated body image concerns, although some tended to regain physical intimacy later on.

Good support from friends and family is crucial for couples with young children facing breast cancer. While emotional support is shown to reduce some of the strains (Fergus \& Gray, 2009; Naaman et al., 2009), practical support in various forms, especially in taking care of young children, is of paramount importance. This would allow the partner to have some time devoted to himself as well as to supporting his ill spouse while she is undergoing surgery or treatment. While some families will have practical support from extended family and close friends, this may not be readily available to all. This is an area for health and social care providers to identify and address sensitively during their interactions with families. The perceptions about the awkwardness and stigma of breast cancer strongly suggest the need for continued efforts at public education.

\section{Conclusion}

Our findings highlight the variability of the perceived impact of breast cancer on couple relationships in families with dependent children and provide valuable insights into the facilitators and barriers to the relationship in these families. While breast cancer can result in a positive impact on relationships for some couples, couples with young children are vulnerable to relationship difficulties, which in turn points to the need for additional psychosocial support tailored to their circumstances. Quantitative studies with large representative samples are needed to assess whether couples with dependent children are more at risk of relationship strain compared with those who do not have dependent children and to ascertain how best they can be supported and helped. Other factors such as frustration and resentment among partners, women's physical and emotional reactions to the illness, differences in communication styles, need for personal space, body image concerns, and social support can all influence couple relationships in families with dependent children. Our results indicate that health and social care professionals 
must be aware of and sensitive to the importance of having an "individual family focus" in their interactions with women and their partners. Universal as well as targeted support and interventions around communication, body image, and sexuality issues will also be of value to women as well as partners.

As cancer survival rates continue to increase, quality of life issues have become increasingly important, and there is a need for understanding relationship vulnerabilities and perceived needs in accordance with the individual circumstances of those who are affected. In addition to large-scale studies of young families that would offer the opportunity to understand their specific needs, studies of health and social care professionals will be helpful to understand the perceived acceptability of options for providing support for couples with dependent children going through relationship difficulties. Some of our findings are generalizable to other forms of cancer as well. Longitudinal studies are important in gaining a better understanding of life after cancer for couples with young families and their support needs throughout the process.

\section{Acknowledgments}

Thanks are due to Denise Brett-Smith for providing research assistance and to the support group convenors, breast care nurses, and those involved from the Breast Cancer Care and Macmillan charities for providing support with recruitment. Thanks are particularly due to the participants for taking the time to give their views openly and honestly.

\section{Funding}

This study was funded by the Breast Cancer Campaign, UK (Grant No. 2009MaySP15).

\section{References}

Ares, I., Lebel, S., \& Bielajew, C. (2014). The impact of motherhood on perceived stress, illness intrusiveness and fear of cancer recurrence in young breast cancer survivors over time. Psychology and Health, 29, 651-670. doi:10.1080/08870446.2014.881998

Badr, H. (2004). Coping in marital dyads: A contextual perspective on the role of gender and health. Personal Relationships, 11, 197-211. doi:10.1111/J.1475-6811.2004.00078.x

Baucom, D., Porter, L., Kirby, J., Gremore, T., \& Keefe, F. (2005). Psychosocial issues confronting young women with breast cancer. Breast Disease, 23, 103-113.

Ben-Zur, H., Gilbar, O., \& Lev, S. (2001). Coping with breast cancer: Patient, spouse, and dyad models. Psychosomatic Medicine, 63, 32-39. doi:10.1097/00006842-200101000-00004

Bloom, J., Stewart, S., Chang, S., \& Banks, P. (2004). Then and now: Quality of life of young breast cancer survivors. Psycho-Oncology, 13, 147-160.

Bloom, J. R., \& Kessler, L. (1994). Risk and timing of counselling and support interventions for younger women with breast cancer. Journal of National Cancer Institute Monograph, 16, 199-206.

Braun, V., \& Clarke, V. (2006). Using thematic analysis in psychology. Qualitative Research in Psychology, 3, 77-101.

Cancer Research, UK. (2013). Breast cancer statistics. http://www.cancerresearchuk.org/healthprofessional/cancer-statistics/statistics-by-cancer-type/breast-cancer [Accessed 04/05/2016] 
Carter, R., Carter, C., \& Siliunas, M. (1993). Marital adaptation and interaction of couples after a mastectomy. Journal of Psychosocial Oncology, 11, 69-81.

Cowan, P., \& Cowan, C. (2000). When partners become parents: The big life change for couples. Mahwah, NJ: Erlbaum.

Coyne, J., \& De Longis, A. (1986). Going beyond social support: The role of social relationships in adaptation. Journal of Consulting and Clinical Psychology, 54, 454-460. doi:10.1037/0022006X.54.4.454

Coyne, J. C., \& Anderson, K. K. (1999). Marital status, marital satisfaction, and support processes among women at high risk for breast cancer. Journal of Family Psychology, 13, 629641. doi:10.1037/0893-3200.13.4.629

Dorval, M., Maunsell, E., Taylor-Brown, J., \& Kilpatrick, M. (1999). Marital stability after breast cancer. Journal of the National Cancer Institute, 91, 54-59.

Dunn, J., \& Steginga, S. (2000). Young women's experience of breast cancer: Defining young and identifying concerns. Psycho-Oncology, 9, 137-146. doi:10.1002/(SICI)1099-1611(200003/04) 9:2<137::AID-PON442>3.0.CO;2-0

Fergus, K., \& Gray, R. (2009). Relationship vulnerabilities during breast cancer: Patient and partner perspectives. Psycho-Oncology, 18, 1311-1322. doi:10.1002/pon.1555

Forrest, G., Plumb, C., Ziebland, S., \& Stein, S. (2009). Breast cancer in young families: A qualitative interview study of fathers and their role and communication with their children following the diagnosis of maternal breast cancer. Psycho-Oncology, 18, 96-103. doi:10.1002/ pon. 1387

Foy, S., \& Rose, K. (2001). Men's experiences of their partner's primary and recurrent breast cancer. European Journal of Oncology Nursing, 5, 42-48.

Ganz, P., Greendale, G., Petersen, L., Kahn, B., \& Bower, J. (2003). Breast cancer in younger women: Reproductive and late health effects of treatment. Journal of Clinical Oncology, 21, $4184-4193$.

Ganz, P., Rowland, H., Desmond, K., Meyerowitz, E., \& Wyatt, E. (1998). Life after breast cancer: Understanding women's health-related quality of life and sexual functioning. Journal of Clinical Oncology, 16, 501-514.

Ghizzani, A., Pirtoli, L., Bellezza, A., \& Velicogna, F. (1995). The evaluation of some factors influencing the sexual life of women affected by breast cancer. Journal of Sex and Marital Therapy, 21, 57-63. doi:10.1080/00926239508405972

Gray, R., Fitch, M., Davis, C., \& Phillips, C. (1997). A qualitative study of breast cancer self-help groups. Psycho-Oncology, 6, 279-289.

Hilton, B., Crawford, J., \& Tarko, M. (2000). Men's perspectives on individual and family coping with their wives' breast cancer and chemotherapy. Western Journal of Nursing Research, 22, 438-495.

Holmberg, S., Scott, L., Alexy, W., \& Fife, B. (2001). Relationship issues of women with breast cancer. Cancer Nursing, 24, 53-60.

Lichtman, R., Taylor, S., \& Wood, J. (1987). Social support and marital adjustment after breast cancer. Journal of Psychosocial Oncology, 5, 47-74. doi:10.1300/J077v05n03_03

Lindholm, L., Rehnsfeldt, A., Arman, M., \& Hamrin, E. (2002). Significant others' experience of suffering when living with women with breast cancer. Scandinavian Journal of Caring Sciences (Special Issue: The Challenging Complexity of Cancer Care Research), 16, 248-255.

Manne, S. (1998). Cancer in the marital context: A review of the literature. Cancer Investigation, 16(3), 188-202.

Manne, S., \& Badr, H. (2008). Intimacy and relationship processes in couples' psychosocial adaptation to cancer. Cancer, 112, 2541-2555. doi:10.1002/cncr.23450 
Manne, S., Dougherty, J., Veach, S., \& Kless, R. (1999). Hiding worries from one's spouse: Protective buffering among cancer patients and their spouses. Cancer Research, Therapy and Control, 8, 175-188.

Manne, S., Ostroff, J., Norton, T., Fox, K., Goldstein, L., \& Grana, G. (2006). Cancer related relationship communication in couples coping with early stage breast cancer. Psycho-Oncology, $15,234-247$.

Manne, S., Ostroff, J., Rini, C., Foxm, K., Goldstein, L., \& Grana, G. (2004). The interpersonal process model of intimacy: The role of self-disclosure, partner disclosure, and partner responsiveness in interactions between breast cancer patients and their partners. Journal of Family Psychology, 18, 589-599.

Minuchin, S. (1974). Families and family therapy. Cambridge, MA: Harvard University Press.

Moyer, A., \& Salovey, P. (1999). Predictors of social support and psychological distress in women with breast cancer. Journal of Health Psychology, 4, 177-191.

Naaman, S., Radwan, K., \& Johnson, S. (2009). Coping with early breast cancer: Couple adjustment processes and couple-based intervention. Psychiatry, 72, 321-345. doi:10.1521/ psyc.2009.72.4.321

Nakaya, N., Saito-Nakaya, K., Bidstrup, P., Dalton, S., Frederiksen, K., Steding-Jessen, M., Uchitomi, Y., \& Johansen, C. (2010). Increased risk of severe depression in male partners of women with breast cancer. Cancer, 116, 5527-5534. doi:10.1002/cncr.25534

Northouse, L. (1989). The impact of breast cancer on patients and husbands. Cancer Nursing, $12,276-284$

Northouse, L. (1994). Breast cancer in younger women: Effects on interpersonal and family relations. Journal of the National Cancer Institute Monographs, 16, 183-190.

Northouse, L. L. (1988). Social support in patients' and husbands adjustment to breast cancer. Nursing Research, 37, 91-95.

Northouse, L. L., Templin, T., Mood, D., \& Oberst, M. (1998). Couples' adjustment to breast cancer and benign breast disease: A longitudinal analysis. Psycho-Oncology, 7, 37-48.

Omne-Ponten, M., Holmberg, L., Bergstrom, R., Sjoden, P., \& Burns, T. (1993). Psychosocial adjustment among husbands of women treated for breast cancer: Mastectomy vs. breast conserving surgery. European Journal of Cancer, 29, 1393-1397.

Pistrang, N., \& Barker, C. (1995). The partner relationship in psychological response to breast cancer. Social Science and Medicine, 40, 789-797.

Rayson, D. (2001). Adjuvant chemotherapy for women with young children: Our patients as parents. Journal of Clinical Oncology, 19, 279-281.

Rodin, G., Lloyd, N., Katz, M., Green, E., Mackay, J., \& Wong, R. (2007). The treatment of depression in cancer patients: A systematic review. Supportive Care in Cancer, 15, 123-136.

Rottmann, N., Hansen, D. G., Larsen, P. V., Nicolaisen, A., Flyger, H., Johansen, C., \& Hagedoorn, M. (2015). Dyadic coping within couples dealing with breast cancer: A longitudinal, population-based study. Health Psychology, 34, 486-495. doi:10.1037/hea0000218

Semple, C. J., \& McCance, T. (2010). Parents' experience of cancer who have young children: A literature review. Cancer Nursing, 33(2), 110-118. doi:10.1097/NCC.0b013e3181c024bb

Skerrett, K. (1998). Couple adjustment to the experience of breast cancer. Families, Systems and Health, 16, 281-298.

Stanton, A., Danoff-Burg, S., Cameron, C., Bishop, M., Collins, C., Kirk, S., Sworowksi, L., \& Twillman, R. (2000). Emotionally expressive coping predicts psychological and physical adjustment to breast cancer. Journal of Clinical and Consulting Psychology, 68, 875-882.

Stiffler, D., Haase, J., Hosei, B., \& Barada, B. (2008). Parenting experiences with adolescent daughters when mothers have breast cancer. Oncology Nursing Forum, 35, 113-120. 
Traa, M. J., De Vries, J., Bodenmann, G., Den Oudsten, B. L. (2015). Dyadic coping and relationship functioning in couples coping with cancer: A systematic review. British Journal of Health Psychology, 20, 85-114. doi:10.1111/bjhp.12094

Twenge, J., Campbell, W., \& Foster, C. (2003). Parenthood and marital satisfaction: A metaanalytic review. Journal of Marriage and Family, 65, 574-583. doi:10.1111/j.17413737.2003.00574.x

Wai Ming, V. (2002). Psychological predictors of marital adjustment in breast cancer patients. Psychology, Health and Medicine, 7, 37-51. doi:10.1080/13548500120101540

Walsh, S., Manuel, J., \& Avis, N. (2005). The impact of breast cancer on younger women's relationships with their partner and children. Families, Systems \& Health, 23, 80-93. doi:10.1037/1091-7527.23.1.80

Watson, M., St. James-Roberts, I., Ashley, S., Tilney, C., Brougham, B., Edwards, L., Baldus, C., \& Romer, G. (2006). Factors associated with emotional and behavioural problems among school age children of breast cancer patients. British Journal of Cancer, 94(1), 43-50. http://doi.org/10.1038/sj.bjc.6602887

Weihs, K., Enright, T., \& Simmens, S. (2002). High quality spousal or long term partner relationships predict time to recurrence of breast cancer, after control for disease severity. Psychosomatic Medicine, 64, 107.

Whitchurch, G., \& Constantine, L. (1993). Systems Theory. In P. Boss, W. Doherty, R. LaRossa, W. Schumm, \& S. Steinmetz (ed.), Sourcebook of family theories and methods: A contextual approach (pp. 325-352). New York: Plenum Press.

Zunkel, G. (2002). Relational coping processes: Couples' response to a diagnosis of early breast cancer. Journal of Psychosocial Oncology, 20, 39-55. doi:10.1300/J077v20n04_03 